WHAT'S

HAPPENING IN
Neurology

Neuroimmunology.

\& Neuroinflammation

\title{
Abstracts
}

Articles appearing in the January 2018 issue

\section{Impaired T-cell migration to the CNS under fingolimod and dimethyl fumarate}

Objective To evaluate the long-term effects of treatments used in multiple sclerosis (MS) on the T-cell trafficking profile.

Methods We enrolled 83 patients with MS under fingolimod (FTY), natalizumab (NTZ), dimethyl fumarate (DMF), or other disease-modifying treatments (DMTs). Blood was drawn before treatment onset and up to 36-48 months. The ex vivo expression of CNS-related integrins ( $\alpha 4 \beta 1$ and $\alpha$ L subunit of LFA-1) and the gutrelated integrin ( $\alpha 4 \beta 7$ ) was assessed using flow cytometry on $\mathrm{CD} 4^{+}$and $\mathrm{CD} 8^{+} \mathrm{T}$ cells. The adhesion profiles of $\mathrm{CD}^{+} \mathrm{T}$ cells to specific integrin ligands (vascular cell adhesion molecule-1 [VCAM-1], intercellular adhesion molecule-1 [ICAM-1], and mucosal vascular addressin cell adhesion molecule-1 [MAdCAM-1]) were measured in vitro before and after 12 and 36-48 months.

Results NTZ decreased the frequency of $\alpha 4 \beta 1+$ and $\alpha 4 \beta 7+$ integrin-expressing $T$ cells and the binding of these cells to VCAM-1 and MAdCAM-1, respectively. After 12 months, DMF induced a decreased frequency of $\alpha$ LhighCD $4^{+} \mathrm{T}$ cells combined with reduced binding to ICAM-1. By contrast, with FTY, there was a doubling of the frequency of $\alpha 4 \beta 1+$ and $\alpha$ Lhigh, but a decreased frequency of $\alpha 4 \beta 7+$ T cells. Strikingly, the binding of $\alpha 4 \beta 1+, \alpha 4 \beta 7+$, and to a lesser extent of $\alpha$ Lhigh T cells to VCAM-1, MAdCAM-1, and ICAM-1, respectively, was decreased at month 12 under FTY treatment. The presence of manganese partially restored the binding of these T cells to VCAM-1 in vitro, suggesting that FTY interferes with integrin activation.

Conclusions In addition to NTZ, DMF and FTY but not other tested DMTs may also decrease T cell-mediated immune surveillance of the CNS. Whether this mechanism may contribute to the onset of CNS opportunistic infections remains to be shown.

NPub.org/N2/9006a

\section{MerTK-mediated regulation of myelin phagocytosis by macrophages generated from patients with MS}

Objective To document functional differences between monocyte-derived macrophages (MDMs) of patients with multiple sclerosis (MS) and the ability of age-/sex-matched healthy donor cells to phagocytose human myelin and to investigate the molecular mechanisms that underlie this.

Methods MDMs were derived from peripheral blood monocytes of 25 untreated patients with relapsing-remitting MS and secondary progressive MS and age-/sex-matched healthy controls (HCs). Phagocytosis was assessed by flow cytometry using fluorescently labeled human myelin. Quantification of messenger RNA and protein expression of Tyro3, Axl, and MerTK family molecules was determined by quantitative PCR, Western blotting, and flow cytometry.

Results Cells of patients with MS display a reduced ability to phagocytose human myelin but not red blood cells as compared to matched HCs. These cells express significantly lower levels of the phagocytic tyrosine kinase receptor, MerTK, and its natural ligand, growth arrest-specific 6, independently of the activation state of the cells. Increased expression of interleukin-10 following myelin uptake by healthy donor cells is lost in MDMs of patients with MS; this effect is mediated through the MerTK pathway. Treatment of MS cells with transforming growth factor $\beta$ (TGF $\beta$ ) restored both phagocytosis and expression deficits.

Conclusions We describe a molecular mechanism that underlies a defect in myelin phagocytosis by macrophages generated from patients with MS. This abnormality involves decreased expression of MerTK and its ligands and can be rescued by treatment with TGF $\beta$.

NPub.org/N2/9006b 


\section{Neurology}

\section{What's happening in Neurology ${ }^{\circledR}$ Neuroimmunology \& Neuroinflammation Neurology 2018;90;273 \\ DOI 10.1212/WNL.0000000000004942}

This information is current as of February 5, 2018

Updated Information \& Services

Permissions \& Licensing

Reprints including high resolution figures, can be found at: http://n.neurology.org/content/90/6/273.full

Information about reproducing this article in parts (figures,tables) or in its entirety can be found online at:

http://www.neurology.org/about/about_the_journal\#permissions

Information about ordering reprints can be found online:

http://n.neurology.org/subscribers/advertise

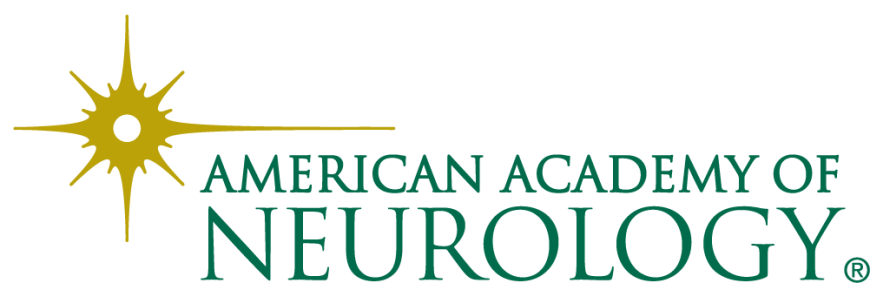

